\title{
Diazinon resistance in Lucilia cuprina; mapping of a fitness modifier
}

\author{
J. A. McKenzie and \\ A. Y. Game*
}

Department of Genetics, University of Melbourne, Parkville, Victoria 3052, Australia:

\begin{abstract}
Modification of the fitness of diazinon resistance genotypes of the Australian sheep blowfly, Lucilia cuprina, in the absence of the insecticide from $\mathrm{SS}>\mathrm{RS}>\mathrm{RR}$ to $\mathrm{SS}=\mathbf{R S}=\mathbf{R R}$ (McKenzie $e t$ al., 1982) has been shown previously to be due to the segregation of a gene(s) on chromosome III (McKenzie and Purvis, 1984). In this study the gene (gene complex) is mapped to the $w$ locus region of that chromosome by comparing changes in frequency of SS individuals in population cages initiated with RS genotypes segregating for field derived regions of chromosome III. Comparison of percentage egg hatch, the percentage of first instar larvae reaching adulthood and the time of development from egg to adult for combinations of modifier and resistance genotypes show that the modifier affects only the latter.

Developmental time is decreased for RS and RR genotypes. The effect is dominant. The developmental time of SS genotypes is unaffected by modifier genotype.
\end{abstract}

\section{INTRODUCTION}

The substitution of a pesticide resistant allele ( $R$ ) at a locus previously fixed for a susceptible allele (S) influences the biochemical and physiological processes associated with development (Brown and Pal, 1971; Clarke and McKenzie, 1987). However, while the rarity of $\mathrm{R}$ alleles in a population before a pesticide is used indicates that resistant individuals must be at a selective disadvantage in the absence of the pesticide, the effect on fitness in arthropods may be small (Roush and McKenzie, 1987). Any deleterious effects may be further minimised by selection for integration of resistance genes into an appropriate genetic background (Abedi and Brown, 1960; Georghiou, 1972; McEnroe and Naegle, 1968). In either circumstance it is apparent that the comparison of the fitness of resistance genotypes should be made in a common genetic background (Roush and McKenzie, 1987) which may be best achieved through a regime of repeated backcrossing (Georghiou, 1969).

Five studies have used this technique to compare fitness of resistance genotypes in arthropods (Helle, 1965; McKenzie et al., 1982; Amin and White, 1984; Whitehead et al., 1985; Beeman and

* Present address: CSIRO, Division of Entomology, P.O. Box 1700, Canberra, A.C.T. 2601, Australia.
Nanis, 1986); only one (McKenzie et al., 1982) provided evidence of co-adaptation with enhanced relative fitness of the $\mathrm{R}$ allele following modification of the genetic background. In that study it was found that RR, RS and SS organophosphorus (diazinon) resistance genotypes had similar fitness in the absence of the chemical when derived from the field in the late $1970 \mathrm{~s}$, some 15 years after resistance to diazinon first evolved. Disruption of the field genetic background by repeated backcrossing of heterozygotes to a laboratory SS strain resulted in a lowering of fitness of resistant genotypes such that after 9 generations of backcrossirig their fitness was similar to that when resistance first evolved (McKenzie et al., 1982; Roush and Croft, 1986; Roush and McKenzie, 1987). Chromosome substitution line analysis showed the gene(s) controlling this fitness modification to be on chromosome III (McKenzie and Purvis, 1984) unlinked to the diazinon resistance locus on chromosome IV (Foster et al., 1981).

This paper reports on the intra-chromosomal mapping of the fitness modifier using population cage analysis and by estimating the influence of the modifier on single generation fitness comparisons between the diazinon resistance genotypes. The results are considered for their relevance to an understanding of the evolution of 
insecticide resistance and, more generally, to the importance of genetic background in the evolutionary process (Fisher, 1958; Maynard Smith et al., 1985).

\section{MATERIALS AND METHODS}

\section{Strains}

The marker strains, with the position of markers on chromosome III, are shown in fig. 1. Each marker strain was SS at the diazinon resistance locus. The marker loci gave the phenotypes crook bristle $(c k)$, white eyes $(w)$, rusty body $(r u)$, molten eye $(m e)$, arista $(a r)$, yellowish eye $(y w)$ and wavy wing $(w y)$ respectively. The marker strains were kindly provided by the CSIRO Division of Entomology, Canberra.

A pure breeding resistant ( $R R$ ) strain, $83 \mathrm{~B}$, was derived from field inseminated females collected in Gippsland, Victoria in 1983. The diazinon resistance genotype of this strain is the same as that used in the previous studies of fitness modification (McKenzie et al., 1982; McKenzie and Purvis,
1984), that is, it is fixed for the $R_{1 A}$ allele of the diazinon resistance locus (McKenzie et al., 1980). This strain was in the laboratory for approximately 10 generations before the current experiments began and was crossed to the marker strains to produce genotypes for use in population cage and single generation fitness studies. A susceptible laboratory reference strain, SWT, SS at the diazinon resistance locus, was also used in crosses to generate genotypes for the single generation fitness comparisons.

\section{Establishment of population cages}

Females of the marker strains were crossed to males of the resistant stock. $F_{1}$ females were backcrossed to the appropriate marker stock and the progeny allocated to phenotypic classes for each chromosome region on the basis of marker segregation. Males and females of each class were treated with $0.5 \mu l$ of 0.01 per cent $(\mathrm{v} / \mathrm{v})$ diazinon to discriminate RS and SS genotypes (McKenzie et al., 1982) and discrete generation population cages for each phenotypic class initiated with RS flies.

CHROMOSOME III MARKERS

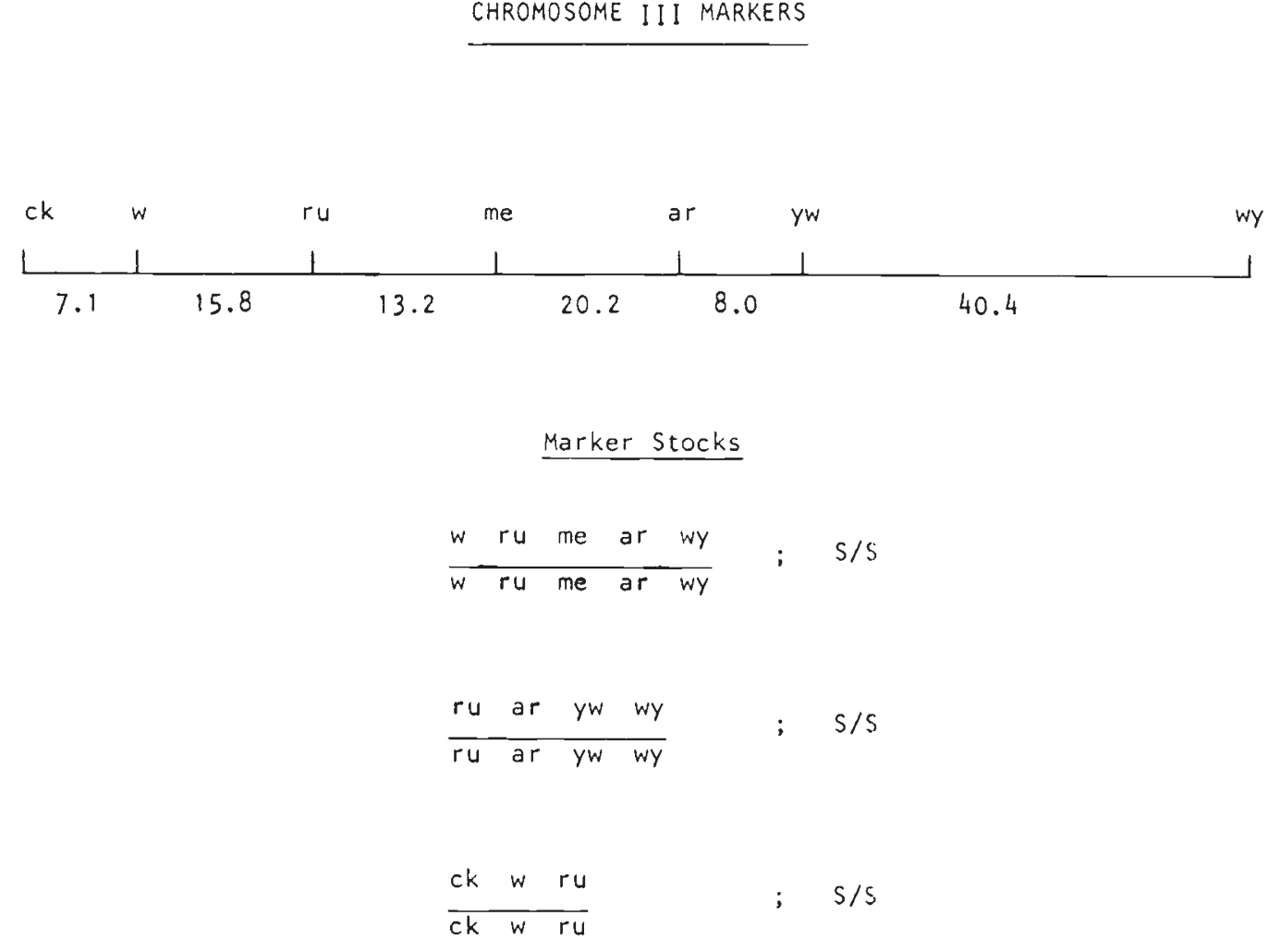

Figure 1 Positions of chromosome III markers of susceptible marker strains used to map the fitness modifier. 
Three trials were run for each class. The $w$ ru me ar wy and ru ar $y w$ wy crosses were carried out in 1984; the $c k w r u$ cross 12 months later.

The initial crosses involving wrumearwy failed to produce sufficient $w+$ me ar wy: RS progeny to establish population cages. The cross was therefore repeated several months later to enable these cages to be started. As a control +++++ ; RS segregants from this cross were used to establish population cages at the same time. Two trials were run for each comparison.

\section{Population cage maintenance and monitoring of resistance status}

Discrete generation population cages were maintained each generation from the progeny of 40 randomly chosen flies of each sex and were kept under standard laboratory conditions (Whitten et al., 1975).

The proportion of SS individuals in each cage at each generation was estimated by testing random samples of 25 males and females with $0.5 \mu$ of 0.01 per cent $(\mathrm{v} / \mathrm{v})$ diazinon and scoring the number of flies dead out of the 50 tested 24 hours later.

\section{Single generation fitness estimates}

The 9 possible genotypic combinations of modifier and resistance genotypes were scored for percentage egg hatch, percentage of 100 first instar larvae that developed on standard medium through larval and pupal stages to emerge as adults (developmental percentage) and the time, in days, from egg to adult (developmental time).

The crossing procedures to produce the parental strains $((1)-(6))$ used to generate the 9 genotypes for testing are given in fig. 2 .

Strains (1) to (4) were used in the first series of experiments in which the absence of the modifier was scored by the presence of the white eye phenotype. In these experiments 50 estimates were made for each fitness comparison for each genotype.

The procedure was repeated with the 9 genotypes produced from crosses between parental strains (3), (4), (5) and (6) (fig. 2). Thirty estimates were made for each fitness comparison for each genotype in this case.

\section{Egg hatch}

Single inseminated females were allowed to lay on a small piece of liver. Eggs were removed from the liver with a brush moistened in water and placed on a moist filter paper in a $7 \mathrm{~cm}$ diameter petri dish. The percentage of eggs hatching after 24 hours at $27^{\circ} \mathrm{C}$ was recorded.

\section{Developmental percentage and time}

One hundred first instar larvae were collected and placed on $110 \mathrm{ml}$ of standard medium in paper cups held on vermiculite in plastic containers. After pupation in vermiculite the number of flies eclosing was recorded as was the time to emergence. The experiments were conducted at $27^{\circ} \mathrm{C}$.

\section{RESULTS}

\section{Population cages}

In the population cages started from the testcross progeny of ruar $y w w y$ and $w$ ru me ar wy with the resistant strain, similar trends were observed for each trial. The standard error ranges for related population cages at a particular generation were $0 \cdot 59-13 \cdot 74$ and $0 \cdot 00-12 \cdot 58$, on the angular scale, respectively.

The ruar $y w$ wy derived cages give relatively constant SS percentages across generations for the ++++ and + ar $y w$ wy comparisons. In all other cases the percentage of SS increases with generation number. There is excellent agreement betweeen the trends of the pooled data for regions of segregation of field material (fig. 3). Thus, the $\mathrm{SS}, \mathrm{RS}$ and RR genotypes have similar fitness when field derived genetic material is from the left arm of chromosome III, marked in this case by the ru marker.

More precise localisation is possible using the data of the population cages derived from the w ru me ar wy strain. The results are again consistent. The percentage of SS individuals increases over generations for all but the +++++ and + rumearwy comparisons in which it remains approximately constant (fig. 4). Confirmation of these results is gained from the $w+$ me ar $w y$ and + ++++ cages of the later experiment (table 1$)$.

Thus, the results of these experiments (figs. 3 and 4 ; table 1) are consistent with the gene(s) responsible for fitness modification segregating with the $w$ marker region of chromosome III. This is substantiated by the data of the population cages started with testcross progeny of the $c k w r u$ and resistant parental strains.

There was again good agreement between the trials (the standard error range, in angular scale, for related population cages of a particular generation being $0 \cdot 00-6 \cdot 20$ ) and between the 


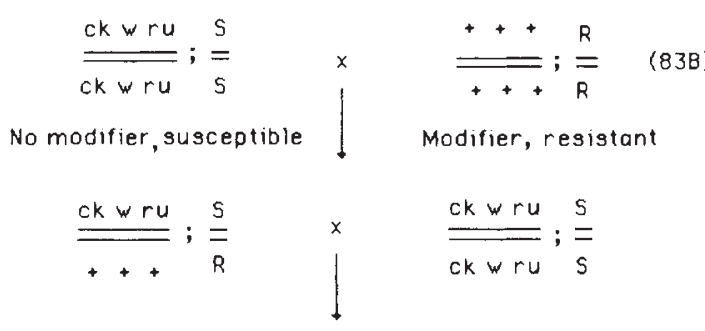

Screen phenotype with $0.01 \%(v / v)$ diazinon

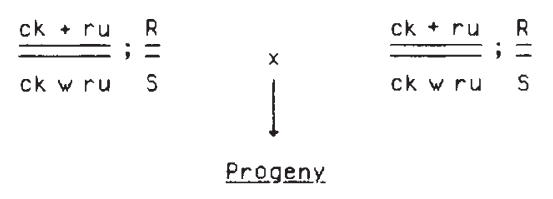

* Establish single pair matings. Identify mating combinations

(1) $-(4)$ by testing flies of each class with $0.01 \%(v / v)$ and/or

$0.025 \%(v / v)$ diazinon and by progeny testing for presence of w allele in crosses (3) and (4).

(1)

(2)

(3)

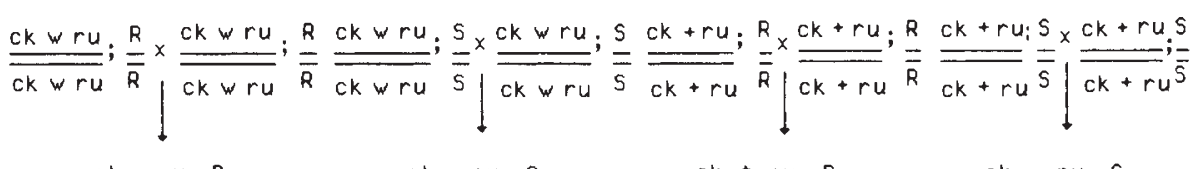
$\frac{c k w r u}{c k w r u} ; \frac{R}{R}$
$\frac{c k w r u}{c k w r u} ; \frac{s}{s}$
$\frac{c k+r u}{c k+r u} ; \frac{R}{R}$
$\frac{c k+r u}{c k+r u} ; \frac{s}{s}$

No modifier, resistant No modifier, susceptible Modifier, resistant Modifier, susceptible

$$
\begin{array}{lll}
\frac{c k w r u}{c k w r u} ; \frac{R}{R} & = & +++
\end{array} \text {; sS (SWT) }
$$

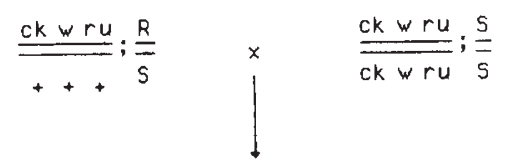

screen phenotype with $0.01 \%(v / v)$ diazinon

$$
\frac{c k+r u}{c k w r u} ; \frac{R}{s} \times \frac{c k+r u}{c k w r u} ; \frac{R}{s}
$$

Progeny

Then proceed as * above

(5)

(6)

$$
\frac{c k+r u}{c k+r u} ; \frac{R}{R} \quad \frac{c k+r u}{c k+r u} ; \frac{s}{5}
$$

No modifier, resistant No modifier, susceptible

Figure 2 Crossing and testing procedure to establish homozygous combinations of modifier and resistance genotypes used to generate genotypes for the single generation fitness experiments. 


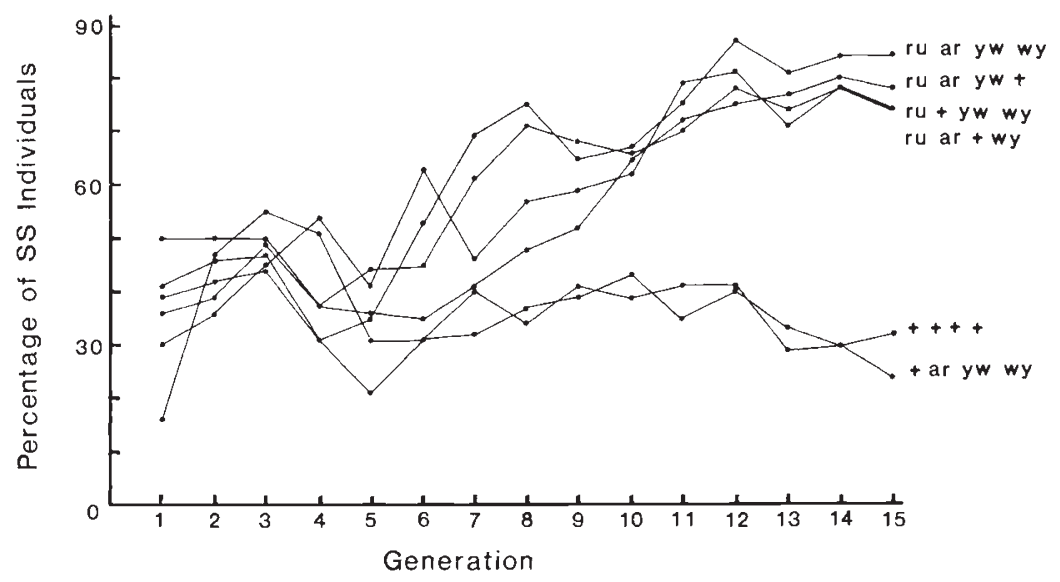

Figure 3 Percentage of SS individuals, averaged over three trials, at each generation in population cages established from classes of RS testcross progeny of

$$
\frac{++++}{++++} ; \operatorname{RR} \text { and } \frac{\operatorname{ruar} y w w y}{\operatorname{ruaryw} w y} ; S S
$$

parental strains.

comparison of cages from the pooled results (fig. 5). The percentage of SS individuals increases across generations when field derived genetic material is not closely linked to the $w$ locus. When this region segregates for field material the percentage of SS individuals in population cages remains essentially the same over generations (fig. 5).

Overall, the difference in trends between population cages with and without field material of the $w$ region is unambiguous (figs. 3,4 and 5; table
1). When this region derives from the field, SS frequency remains constant, when it does not, SS frequency increases with cage generation.

\section{Single generation fitness estimates}

The results of the two experiments are given in tables 2 and 3 with the associated analyses in tables 4 and 5 respectively. The data of table 2 are more applicable to the population cage studies where

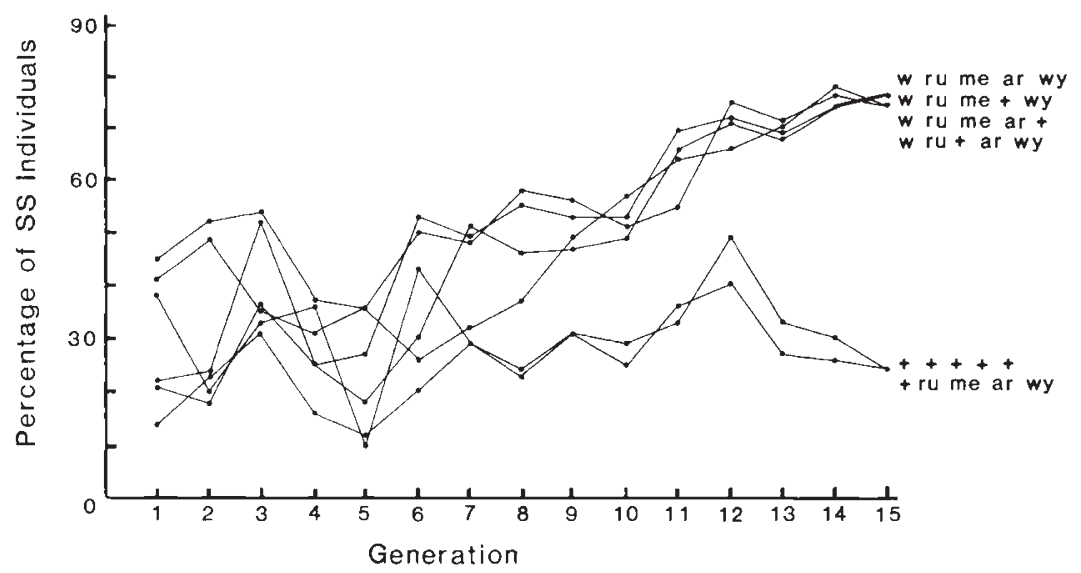

Figure 4 Percentage of SS individuals, averaged over three trials, at each generation in population cages established from classes of RS testcross progeny of

$$
\frac{+++++}{+++++} ; \mathrm{RR} \text { and } \frac{\text { wrumearwy }}{\text { wrumearwy }} ; \mathrm{SS}
$$

parental strains. 
Table 1 Mean $(\bar{x})$ percentage of SS individuals, averaged over two trials at specified generations of population cages established from

$$
w+\frac{\text { mear } w y}{\text { wrume arwy }} ; \mathrm{RS} \text { or } \frac{+++++}{\text { wrumear } w y} ; \mathrm{RS}
$$

genotypes. Standard errors (S.E.) are in angular scale

\begin{tabular}{|c|c|c|c|c|}
\hline \multirow[b]{2}{*}{ Generation } & \multicolumn{2}{|c|}{$w+$ me ar wy } & \multicolumn{2}{|c|}{++++} \\
\hline & $\bar{x}$ & S.E. & $\bar{x}$ & S.E. \\
\hline 1 & $29 \cdot 0$ & 0.63 & $21 \cdot 0$ & 0.70 \\
\hline 5 & $39 \cdot 0$ & 1.77 & $29 \cdot 0$ & $3 \cdot 17$ \\
\hline 10 & $50 \cdot 0$ & $1 \cdot 15$ & $28 \cdot 0$ & $0 \cdot 0$ \\
\hline 15 & $64 \cdot 0$ & $1 \cdot 20$ & $31 \cdot 0$ & $0 \cdot 62$ \\
\hline
\end{tabular}

the $w$ marker is segregating, however, the results are similar whether or not the modifier region is identified by this marker.

There is no consistent trend or significant difference between modifier region or resistance genotypes for developmental percentage. There is some suggestion that the modifier region genotypes may influence egg hatch of RS and RR (tables 2

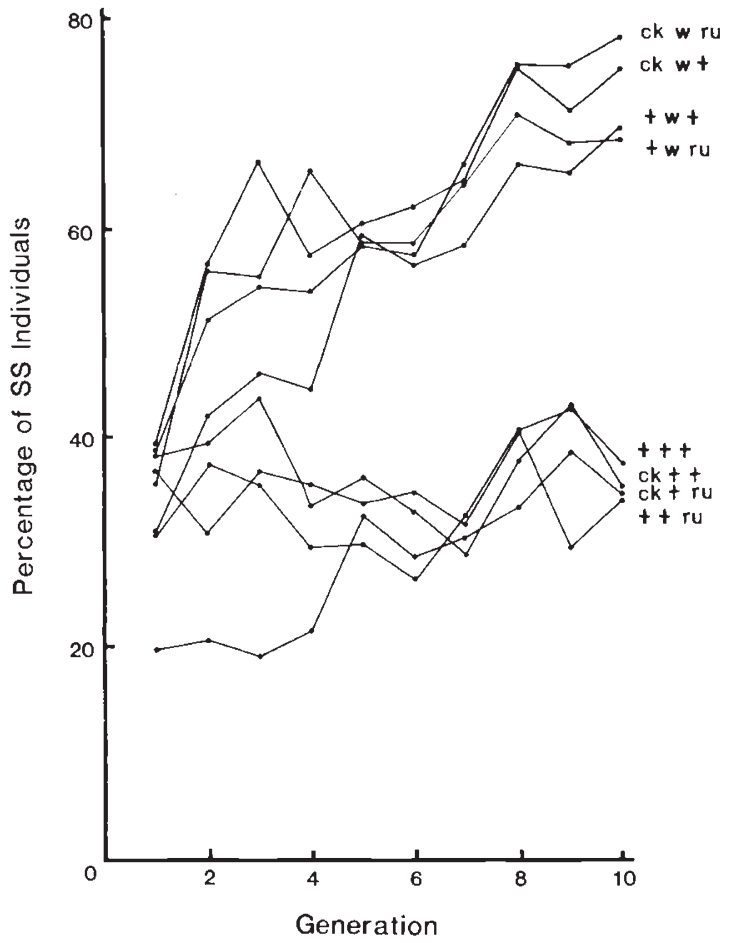

Figure 5 Percentage of SS individuals, averaged over three trials, at each generation in population cages established from classes of RS testscross progeny of

$$
\frac{+++}{+++} ; \mathrm{RR} \text { and } \frac{c k w r u}{c k w r u} ; \mathrm{SS}
$$

parental strains. and 3). However, this is only marginally significant for the RR genotype in the $w$ segregation comparison when the data are partitioned (tables 4 and 5) to test the significance of the trends observed in tables 2 and 3.

The developmental times of RS and RR are influenced by genotypes of the modifier region (tables 4 and 5). Inspection of tables 2 and 3 suggests the developmental time of these genotypes is decreased when the modifier is present. The effect is dominant as similar results are observed when the modifier region is "heterozygous" or "homozygous" for field derived genotypes. For the 3 characters considered, SS genotypes are not significantly influenced by genotypes of the modifier region (tables 2-5).

\section{DISCUSSION}

The gene(s) responsible for the fitness modification of diazinon resistance genotypes of $L$. cuprina have been mapped to the $w$ region of chromosome III. When the results of population cages derived from the wrumearwy and ckwru strains are considered together with those of the single generation fitness estimates it is apparent that the modifying gene, or gene complex, is at, or closely linked to, the $w$ locus as co-segregation appears complete.

The mechanistic association between the modifier and the diazinon resistance locus is currently undefined although as the biochemical basis of diazinon resistance is known (Hughes and Devonshire, 1982) it should be possible to address this question specifically in the future. In general terms, it is possible to consider evolutionary models in which there is a re-canalization of development after an initial genetic or environmental perturbation (Waddington, 1957; Maynard Smith et al., 1985).

Clarke and McKenzie (1987) found that the level of fluctuating asymmetry (Van Valen, 1962) in a cyclodiene (dieldrin) resistant strain of $L$. cuprina was significantly greater than for susceptible or diazinon resistant strains. Fluctuating asymmetry increased in the diazinon resistant strain with repeated generations of outcrossing to a laboratory susceptible strain. Outcrossing had no affect on levels of fluctuating asymmetry in the dieldrin resistant strain.

These results suggested that the initial introduction of an $\mathrm{R}$ allele into the field genome causes disruption to the usual developmental processes (Brown and Pal, 1971) resulting in increased developmental "noise" (Waddington et al., 1957) 
Table 2 Mean $(\bar{x})$ percentage egg hatch, developmental percentage (percentage of $1001 \mathrm{st}$ instar larvae reaching the adult stage after development on standard medium) and developmental time (in days) of the specified modifier and resistance genotypes. Presence of the modifier is indicated by + , absence by $w$. Standard errors (S.E.) for egg hatch and developmental percentage are in angular scale

\begin{tabular}{|c|c|c|c|c|c|c|}
\hline \multirow[b]{2}{*}{ Genotype } & \multicolumn{2}{|c|}{ Egg hatch } & \multicolumn{2}{|c|}{$\begin{array}{l}\text { Developmental } \\
\text { percentage }\end{array}$} & \multicolumn{2}{|c|}{$\begin{array}{l}\text { Developmental } \\
\text { time }\end{array}$} \\
\hline & $\bar{x}$ & S.E. & $\bar{x}$ & S.E. & $\bar{x}$ & S.E. \\
\hline$w w ; \mathrm{RR}$ & $52 \cdot 6$ & 3.47 & $50 \cdot 9$ & 1.45 & $13 \cdot 72$ & 0.08 \\
\hline$w w ; \mathrm{RS}$ & $50 \cdot 6$ & $3 \cdot 35$ & $53 \cdot 2$ & 1.71 & $13 \cdot 78$ & 0.08 \\
\hline$w w ; S S$ & $55 \cdot 8$ & $3 \cdot 51$ & $50 \cdot 0$ & $1 \cdot 31$ & $13 \cdot 64$ & 0.07 \\
\hline$w+; \mathrm{RR}$ & $55 \cdot 4$ & 3.60 & $49 \cdot 8$ & $2 \cdot 46$ & $13 \cdot 44$ & 0.07 \\
\hline$w+; \mathrm{RS}$ & $59 \cdot 6$ & $3 \cdot 62$ & $48 \cdot 6$ & $2 \cdot 76$ & $13 \cdot 41$ & 0.08 \\
\hline$w+; \mathrm{SS}$ & $54 \cdot 6$ & 3.68 & $49 \cdot 9$ & $2 \cdot 47$ & $13 \cdot 62$ & 0.08 \\
\hline$++; \mathrm{RR}$ & $69 \cdot 1$ & 3.96 & $46 \cdot 2$ & 1.91 & $13 \cdot 43$ & 0.08 \\
\hline$++; \mathrm{RS}$ & $60 \cdot 1$ & $3 \cdot 84$ & $45 \cdot 0$ & $2 \cdot 77$ & $13 \cdot 45$ & 0.08 \\
\hline$++; \mathrm{SS}$ & $55 \cdot 7$ & $3 \cdot 50$ & $44 \cdot 6$ & $2 \cdot 01$ & $13 \cdot 65$ & 0.08 \\
\hline
\end{tabular}

and therefore increased bilateral asymmetry. Subsequent selection to re-establish normal developmental processes results in levels of asymmetry that are explained by chance perturbations (Waddington, 1957; Van Valen, 1962; Maynard Smith et al., 1985).

The gene(s) responsible for the modification of asymmetry of diazinon resistance genotypes of L. cuprina was mapped to chromosome III (Clarke and McKenzie, 1987) and has been subsequently shown to be the same gene, or gene complex, that modifies the fitness of diazinon resistance genotypes (McKenzie and Clarke, unpublished). Selection for the modifier has enabled the $\mathrm{R}$ allele to become co-adapted into the field genome.

Such co-adaptation of resistance alleles has been implied in a number of studies but a critical review of the literature indicates that the phenomenon is not common (Roush and McKenzie, 1987). Indeed, in $L$. cuprina, there is no evidence that co-adaptation has occurred for the dieldrin resistance allele (Whitten et al., 1980; Clarke and McKenzie, 1987). The most likely explanation for the difference in the co-adaptation of diazinon and dieldrin resistant genotypes relates to the period of use of the insecticides after resistance first evolved.

Dieldrin was used for only 2 years for blowfly control until the development of resistance rendered it ineffective as a protective agent against "flystrike". It was replaced by diazinon which was used as the primary insecticidal control agent for approximately 15 years after resistance to it had developed (McKenzie, 1983). Therefore, in the case of dieldrin resistance a new chemical was substituted for blowfly control soon after resistance evolved so that resistant homozygotes never constituted more than 20 per cent of the population (Hughes and McKenzie, 1986). Continued use of diazinon after resistance evolved to that insecticide

Table 3 Mean $(\bar{x})$ percentage egg hatch, developmental percentage and developmental time (in days) of specified modifier and resistance genotypes. Presence ofmodifier is indicated by $M$, absence by $m$. Standard errors (S.E.) for egghatch and developmental percentage are in angular scale

\begin{tabular}{|c|c|c|c|c|c|c|}
\hline \multirow[b]{2}{*}{ Genotype } & \multicolumn{2}{|c|}{ Egg hatch } & \multicolumn{2}{|c|}{$\begin{array}{l}\text { Developmental } \\
\text { percentage }\end{array}$} & \multicolumn{2}{|c|}{$\begin{array}{l}\text { Developmental } \\
\text { time }\end{array}$} \\
\hline & $\bar{x}$ & S.E. & $\bar{x}$ & S.E. & $\bar{x}$ & S.E. \\
\hline$m m ; \mathrm{RR}$ & $49 \cdot 3$ & $2 \cdot 65$ & $50 \cdot 7$ & $1 \cdot 45$ & $13 \cdot 82$ & 0.05 \\
\hline$m m ; \mathrm{RS}$ & $48 \cdot 6$ & 3.09 & $56 \cdot 7$ & $2 \cdot 42$ & $13 \cdot 74$ & 0.05 \\
\hline$m m ; \mathrm{SS}$ & $52 \cdot 2$ & $3 \cdot 80$ & $49 \cdot 7$ & 1.01 & $13 \cdot 65$ & 0.04 \\
\hline$m M ; \mathrm{RR}$ & $51 \cdot 8$ & $4 \cdot 36$ & $60 \cdot 0$ & 1.92 & $13 \cdot 44$ & 0.06 \\
\hline$m M ; \mathrm{RS}$ & $49 \cdot 4$ & $3 \cdot 04$ & $57 \cdot 4$ & $2 \cdot 06$ & $13 \cdot 52$ & 0.04 \\
\hline$m M ; \mathrm{SS}$ & $51 \cdot 5$ & 3.08 & $57 \cdot 6$ & $1 \cdot 54$ & $13 \cdot 66$ & 0.05 \\
\hline$M M ; \mathrm{RR}$ & $58 \cdot 3$ & $3 \cdot 50$ & $54 \cdot 0$ & $1 \cdot 37$ & $13 \cdot 44$ & 0.03 \\
\hline$M M ; \mathrm{RS}$ & $64 \cdot 3$ & $3 \cdot 69$ & $55 \cdot 1$ & $2 \cdot 02$ & $13 \cdot 45$ & 0.04 \\
\hline$M M ; \mathrm{SS}$ & $52 \cdot 1$ & $3 \cdot 57$ & $50 \cdot 1$ & $2 \cdot 16$ & $13 \cdot 65$ & 0.03 \\
\hline
\end{tabular}


J. A. MCKENZIE AND A. Y. GAME

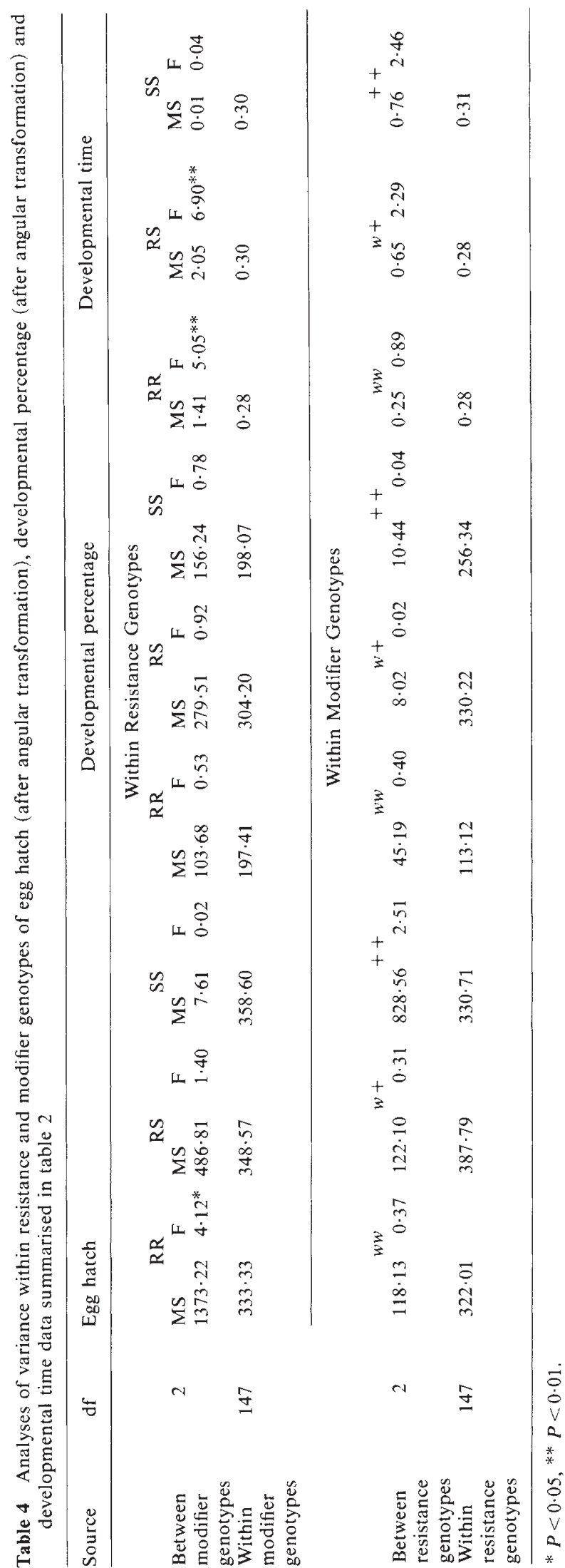




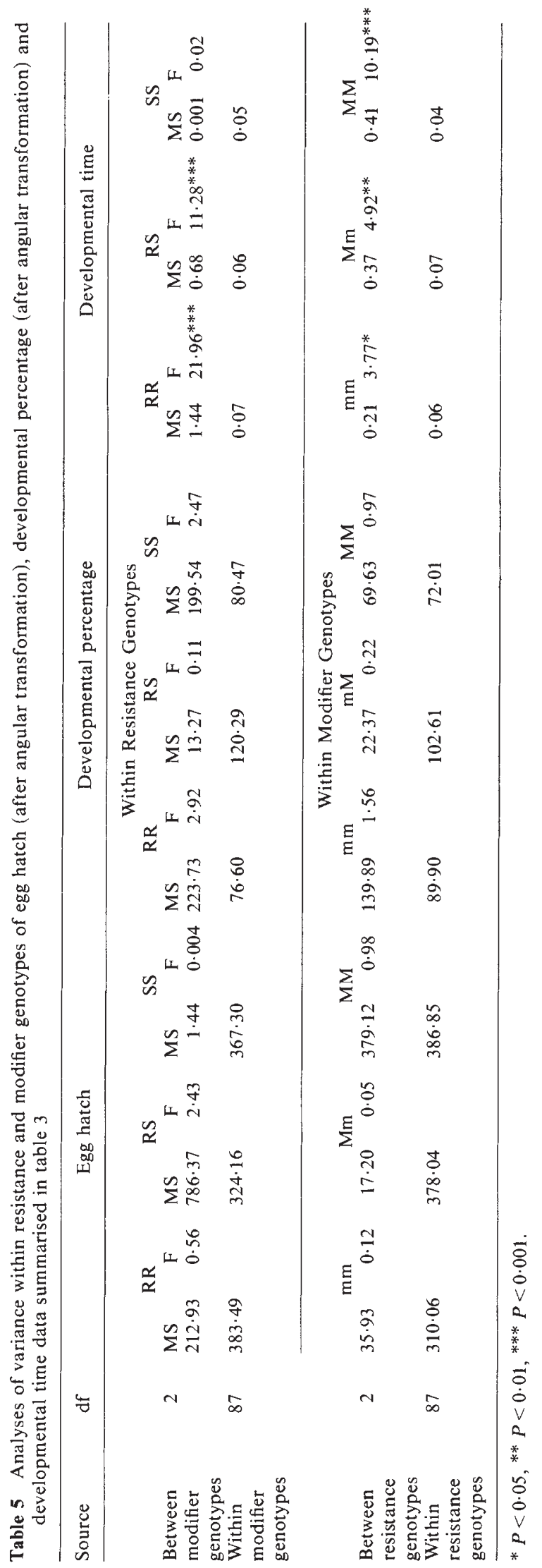


resulted in high frequencies of the resistant allele, reaching near fixation in some populations (McKenzie et al., 1980; McKenzie, 1984).

If the general genetical arguments on the conditions necessary for the selection of fitness modifiers (Fisher, 1958; Charlesworth, 1979) are extended to studies on resistance it is apparent that such modifiers can only be at a selective advantage in the presence of the resistance allele. Selection for fitness modification will be fairly weak until the resistance allele is at a high frequency in the population. Therefore, the appropriate conditions for the evolution of fitness modification existed for diazinon resistant genotypes of $L$. cuprina but did not for genotypes at the dieldrin resistance locus.

More generally, the usual response to resistance in agricultural pests has been to substitute a new control agent when resistance evolves and therefore conditions that enable fitness modification similar to that observed at the diazinon resistance locus of $L$. cuprina have been limited. It is clear, however, that because of difficulties of discovery, development, registration and manufacture of new effective pesticides (Hotson, 1985; Roush and McKenzie, 1987) these conditions may occur more commonly in the future. If these circumstances arise and the opportunity for evolutionary study is taken a further point needs to be made.

The present study has demonstrated the relevance of measuring fitness relationships in a common genetic background. This is especially important if the co-adaption of an $\mathrm{R}$ allele into the field genome is to be considered. It can only be effectively addressed through the use of backcrossing (Georghiou, 1969), or more sophisticated genetical techniques (Lewontin, 1974), unless longitudinal studies, that record changes in the fitness set over time using material derived directly from the field, are undertaken. In systems where some level of genetic manipulation is possible it is our assessment that single generation fitness tests will be most effectively utilised if population cage studies have demonstrated differences in fitness between genotypes, although it must be emphasised that there may be difficulties in estimating fitness by either method (Prout, 1971). Furthermore, caution should be exercised in attempting directly to inter-relate the estimates. For instance, in the present study it may be argued that there is general agreement between the population cage results and those for development time with respect to the localisation and impact of the modifier, however, to ascribe population cage changes of SS frequency purely to differences in developmental rate of the genotypes would be an unacceptable simplification. Additional caution is required if comparative studies of components of fitness of resistance genotypes use strains of unrelated lineage. It is possible that any differences observed will reflect ecotypic variation that is independent of resistance status if the genetic background is not defined (Roush and McKenzie, 1987).

Acknowledgements We wish to thank John Oakeshott, Geoff Clarke and Jenny Fegent for comments on the manuscript and Julie Lycette, Tracey Collings, Joanne Van Eyk, Lachlan Ingram and Tracey Williams for technical assistance at various stages of the study. Financial support was provided by the Australian Research Grants scheme and the Research Trust Fund of the Australian Wool Corporation.

\section{REFERENCES}

ABEDI, Z. H. AND BROWN, A. W. A. 1960. Development and reversion of DDT-resistance in Aedes aegypti. Can. J. Genet. Cytol., 2, 252-261.

AMIN, A. M. AND WHITE, G. B. 1984. Relative fitness of organophosphate-resistant and susceptible strains of $C u l e x$ quinquefasciatus Say (Diptera: Culicidae). Bull. Entomol. Res., 74, 591-598.

BEEMAN, R. W. AND NANIS, S. M. Malathion resistance aileles and their fitness in the red flour beetle (Coleoptera: Tenebrionidae). J. Econ. Entomol., 79, 580-587.

BROWN, A. W. AND PAL, R. 1971. Insecticide Resistance in Arthropods. W.H.O., Geneva.

CHARLESWORTH, B. 1979. Evidence against Fisher's theory of dominance. Nature, 278, 848-849.

CLARKE, G. M. AND MCKENZIE, J. A. 1987. Developmental stability of insecticide resistant phenotypes in blowfly; a result of canalizing natural selection. Nature, 325, 345-346.

F1SHER, R. A. 1958. The Genetical Theory of Natural Selection, 2nd edition. Dover, New York.

FOSTER, G. G., WHITTEN, M. J., KONOVALOV, C., ARNOLD, J. T.A. AND MAFFI, G. 1981. Autosomal genetic maps of the Australian sheep blowfly, Lucilia cuprina dorsalis R-D (Diptera: Calliphoridae) and possible correlations with the linkage maps of Musca domestica L. and Drosophila melanogaster (Mg.). Genet. Res., 37, 55-69.

GEORGHIOU, G. P. 1969. Genetics of resistance to insecticides in houseflies and mosquitoes. Exp. Parasitol., 26, 224-255.

GEORGHIOU, G. P. 1972. The evolution of resistance to pesticides. Ann.Rev. Ecol. Syst., 3, 133-168.

HELLE, W. 1965. Resistance in the acarina: mites. Adv. Acarol, 2, 71-93.

HOTSON, 1. K. 1985. New developments in nematode control: the role of the animal health products industry. In Anderson, N. and Waller, P. J. (eds.) Resistance in Nematodes to Anthelmintic Drugs, CSIRO and Australian Wool Corporation, Sydney, pp. 117-125.

HUGHES, P. B. AND DEVONSHIRE, AL. L. 1982. The biochemical basis of resistance to organophosphorus insecticides in the sheep blowfly, Lucilia cuprina. Pestic. Biochem. Physiol., 18, 289-297. 
HUGHES, P. B. AND MCKENZIE, J. A. 1986. Insecticide resistance in the Australian sheep blowfly, Lucilia cuprina: speculation, science and strategies. In Fundamental and Practical Approaches to Combating Resistance. Proc. Soc. Chem. Industry, London (In Press).

LEWontin, R. C. 1974. The Genetic Basis of Evolutionary Change. Columbia Uni. Press, New York.

MAYNARD SMITH, J., BURIAN, R., KAUFFMAN, S., ALBERCH, P., CAMPBELL, J., GOODWIN, B., LANDE, R., RAUP, D. AND WOLPERT, L. 1985. Developmental constraints and evolution. Quart. Rev. Biol., 60, 266-287.

MCEnRoE, W. D. And NaEgle, J. A. 1968. The coadaptive process in an organophosphorus-resistant strain of the two spotted mite, Tetranychus urticae. Ann. Entomol. Soc. Amer., 61, 1055-1069.

MCKENZIE, J. A. 1983. The evolution of insecticide resistance: consequences for control programmes. In 2 nd National Symposium on Sheep Blowfly and Flystrike in Sheep. Department of Agriculture, N.S.W., pp. 222-231.

MCKENZIE, J. A. 1984. Dieldrin and diazinon resistance in populations of the Australian sheep blowfly, Lucilia cuprina, from sheep-grazing areas and rubbish tips. Aust. J. Biol. Sci., 37, 367-374.

MCKENZIE, J. A. AND PURVIS, A. 1984. Chromosomal localisation of fitness modifiers of diazinon resistance genotypes of Lucilia cuprina. Heredity, 53, 625-634.

MCKENZIE, J. A., DEARN, J. M. AND WHITTEN, M. J. 1980. Genetic basis of resistance to diazinon in Victorian populations of the Australian sheep blowfly, Lucilia cuprina. Aust. J. Biol. Sci., 33, 85-95.
MCKENZIE, J. A., WhitTEN, J. J. AND ADENA, M. A. 1982. The effect of genetic background on the fitness of diazinon resistance genotypes of the Australian sheep blowfly, Lucilia cuprina. Heredity, 49, 1-9.

PROUT, T. 1971. The relation between fitness components and population prediction in Drosophila. 1. The estimation of fitness components. Genetics, 68, 127-149.

ROUSH, R. T. AND CROFT, B. A. 1986. Experimental population genetics and ecological studies of pesticide resistance in insects and mites. In Pesticide Resistance: Strategies and Tactics for Management. National Academy Press, Washington, pp. $257-270$.

ROUSH, R. T. AND MCKENZIE, J. A. 1987. Ecological genetics of insecticide and acaricide resistance. Ann. Rev. Entomol., 32, 361-380.

VAN VALEN, L. 1962. A study of fluctuating asymmetry. Evolution, 16, 125-142.

WAddington, C. H. 1957. The Strategy of the Genes. Allen and Unwin, London.

WADDINGTON, C. H., GRABER, H. AND WOOLF, B. 1957. Isoalleles and the response to selection. J. Genet., 55, 246-250.

WHITEHEAD, J. R., ROUSH, R. T., NORMENT, B. R. 1985. Resistance stability and coadaptation in diazinon-resistant house flies (Diptera: Muscidae). J. Econ. Entomol, 78, 25-29.

WhitTEN, M. J., DEARN, J. M. AND MCKENZIE, J. A. 1980. Field studies on insecticide resistance in the Australian sheep blowfly, Lucilia cuprina. Aust. J. Biol. Sci., 33, 725735 .

WHITTEN, M. J., FOSTER, G. G., ARNOLD, J. T. AND Konovalov, c. 1975. The Australian sheep blowfly, Lucilia cuprina. In King, R. C. (ed.) Handbook of Genetics, Vol. 3, Plenum, New York, pp. 401-418. 